\title{
Job satisfaction of foreign-national physicians working in patient care: a cross-sectional study in Saxony, Germany
}

\author{
Birte Pantenburg ${ }^{1 *}$, Katharina Kitze ${ }^{2}$, Melanie Luppa ${ }^{1}$, Hans-Helmut König ${ }^{3}$ and Steffi G. Riedel-Heller ${ }^{1}$
}

\begin{abstract}
Background: Physician migration is gaining attention worldwide. Despite increasing numbers of foreign physicians in Germany, their perceptions on working in Germany remain unexplored. Within a large survey on Saxon physicians, the aim of this study was to elucidate whether foreign-national physicians' job satisfaction differed from German physicians' job satisfaction.

Methods: The study was designed as a comprehensive cross-sectional survey. All physicians $\leq 40$ years and registered with the State Chamber of Physicians of Saxony $(n=5956)$ were mailed a paper-pencil questionnaire, of which 2357 were returned (response rate $=40 \%$ ). Questionnaires addressed socio-demographics and assessed job satisfaction by asking participants to rate their satisfaction with the overall job situation and 20 different aspects on a 5-point Likert scale $(1=$ very dissatisfied to $5=$ very satisfied).

Results: Ten percent of participants were foreign-national physicians. The three main countries of origin were the Czech Republic, Slovakia, and Poland. Foreign-national physicians were more satisfied with aspects related to patient care, such as "possibility to treat patients as you deem optimal" and "relationship with patients". However, they were less satisfied with aspects related to human relations, such as "work atmosphere", relationship with co-workers, and "social status". Foreign-national physicians were also less satisfied with the aspect "work enjoyment".

Conclusions: Further research on determinants promoting foreign-national physicians' job satisfaction is needed as their professional well-being may influence quality of patient care. Measures teaching cross-cultural competence and awareness may be beneficial for both foreign-national and German physicians.
\end{abstract}

Keywords: Physicians, Job satisfaction, Migration, Germany

\section{Introduction}

Global physician migration has been gaining increasing attention [1]. The number of foreign physicians working in Germany has risen from 16,818 in 2007 to 21,650 in 2010 , and to 34,706 in 2014 [2]. Vacancies, primarily in rural areas and in eastern Germany, are being filled with immigrant physicians [3]. The State Chamber of Physicians in Saxony underlines foreign physicians' important contributions to the quality of patient care and to safeguarding the operability of hospital wards, especially in rural areas [4]. Thus, foreign physicians play an increasingly important role in the German health care system, above all in the hospital sector [5].

While it has been shown that physicians' professional satisfaction seems to be positively associated with their patients' satisfaction with care [6], data on immigrant physicians' perspectives on their work in Germany are scarce to non-existent. Therefore, in the context of a larger survey on Saxon physicians' job satisfaction [7], burnout [8], and wishes to quit [9], the aim of the present analysis was to elucidate whether foreignnational physicians' job satisfaction differed from German physicians' job satisfaction.

\footnotetext{
* Correspondence: Birte.Pantenburg@medizin.uni-leipzig.de

${ }^{1}$ Institute of Social Medicine, Occupational Health and Public Health,

University of Leipzig, Philipp-Rosenthal-Str. 55, 04103 Leipzig, Germany

Full list of author information is available at the end of the article
} 


\section{Methods}

\section{Study population and study design}

In a cross-sectional survey all physicians $\leq 40$ years and registered with the State Chamber of Physicians of Saxony $(n=5956)$ were sent a paper-pencil questionnaire, accompanied by information about the study's purpose, anonymous design, and that returning the completed questionnaire would be regarded as giving informed consent to participation. From September 2012 to February 2013, 2357 questionnaires were returned (response rate = $40 \%)$. The ethics committee of the University of Leipzig (Ethik-Kommission an der Medizinischen Fakultät der Universität Leipzig) approved the study.

\section{Questionnaire and data analysis}

The questionnaire was developed based on a literature search and on existing instruments as described elsewhere [8]. Briefly, it included questions on sociodemographics, as well as job satisfaction (mainly based on [10], modified considering [11] and [12]), asking participants to rate their satisfaction with the overall job situation and 20 different aspects on a 5-point Likert scale ( $1=$ very dissatisfied to $5=$ very satisfied).

Of the 2357 questionnaires returned, 9 were excluded because they either did not meet the inclusion criteria or were incomplete. The present analysis included $n=1893$ physicians working in patient care who provided an answer (yes/no) to the question "Do you have German citizenship?". Chi ${ }^{2}$-tests and t-tests were used to compare sociodemographic characteristics of participants with and without German citizenship. Means were calculated for each item of the job satisfaction questionnaire and comparisons were performed using t-tests. Data was analysed with Stata 13.0 for Windows.

\section{Results}

\section{Characteristics of the study population}

The characteristics of the study population are detailed in Table 1. Ten percent (192/1893) of the study population reported a citizenship other than German (Table 2).

\section{Work satisfaction of participants with and without German citizenship}

Participants without German citizenship were more satisfied with the "possibility to treat patients as you deem optimal", "relationship with patients", and "equality of men and women". They were less satisfied with the "work atmosphere", "social status", "relationship with colleagues", "relationship with non-medical staff", and "job security". Foreign-national physicians were also less satisfied with the aspect "work enjoyment" (Table 3).
Table 1 Characteristics of the study population

\begin{tabular}{llll}
\hline & Citizenship & & \\
\cline { 2 - 4 } & German $(n=1701)$ & Other $(n=192)$ & $p$ \\
$\%(n)$ & $62.0(119)$ & 0.858 \\
\hline Women & $61.3(1043)$ & $71.9(138)$ & $<0.001$ \\
In relationship & $85.2(1446)$ & $36.7(70)$ & $<0.001$ \\
Has children & $54.5(927)$ & $34.4(66)$ & 0.325 \\
Specialist & $38.0(645)$ & $93.8(180)$ & $<0.001$ \\
Full-time & $83.0(1411)$ & $92.1(174)$ & 0.001 \\
Inpatient setting & $82.5(1377)$ & $69.9(123)$ & 0.026 \\
Urban setting & $77.4(1261)$ & $6.9(13)$ & 0.002 \\
Leading position/ & $15.2(253)$ & & \\
own practice & & M (SD; 95 \% Cl) & \\
& $M(S D ; 95 \%$ Cl) & 32.09 & 0.006 \\
Age (years) & 32.92 & $(4.15 ; 31.50-32.68)$ & \\
Work experience & $5.51(3.75 ; 5.33-5.69)$ & $5.59(3.90 ; 5.03-6.14)$ & 0.785 \\
(years) & & & \\
\hline
\end{tabular}

Results of participants with and without German citizenship were compared and $p$ values are shown. Percentages were calculated with the number of answers actually given. $M$ mean, $S D$ standard deviation, $C l$ confidence interval

\section{Discussion}

Of this sample of physicians in Saxony, $10.1 \%$ stated a citizenship other than German. This is consistent with official Saxon statistics according to which $10.5 \%$ of working physicians were foreign [4]. Also, the source countries in this sample mainly follow official statistics, with the three most important countries being the Czech Republic, Slovakia, and Poland [4].

Data from Germany on immigrant physicians' job satisfaction is extremely limited. In the present study, participants with and without German citizenship did not differ regarding their overall work satisfaction. However, foreign-national participants were more satisfied with aspects related to patient care, such as the "possibility to treat patients as you deem optimal", and "relationship with patients". In previous interviews, 20 Polish physicians named better working conditions, and advanced training or qualification possibilities as important reasons for migrating to Germany [13]. Similarly, better working environment, access to specialist training, as well as equipment available in German hospitals, was an important reason for physicians migrating from countries such as Austria, Bulgaria, India, Iraq, Latvia, Mongolia, and Syria [14]. If expectations are met, this may contribute to immigrant physicians' relatively higher satisfaction with the possibility for optimal treatment and subsequently, their doctor-patient-relationship. Although higher wages have also been identified as a major incentive for migration to Germany [13, 14], there was 
Table 2 Country of citizenship of foreign-national physicians

\begin{tabular}{|c|c|}
\hline Country & $\%(n)$ \\
\hline Czech Republic & $16.1(31)$ \\
\hline Slovakia & $13.5(26)$ \\
\hline Poland & $10.4(20)$ \\
\hline Austria & $9.4(18)$ \\
\hline Romania & $8.9(17)$ \\
\hline Hungary & $4.2(8)$ \\
\hline Ukraine & $3.1(6)$ \\
\hline Syria & $2.6(5)$ \\
\hline Bulgaria & $2.1(4)$ \\
\hline Greece & $2.1(4)$ \\
\hline Russia & $2.1(4)$ \\
\hline Lithuania & $1.6(3)$ \\
\hline Bosnia & $1.0(2)$ \\
\hline France & $1.0(2)$ \\
\hline Italy & $1.0(2)$ \\
\hline Moldova & $1.0(2)$ \\
\hline Azerbaijan & $0.5(1)$ \\
\hline Belarus & $0.5(1)$ \\
\hline Georgian Republic & $0.5(1)$ \\
\hline India & $0.5(1)$ \\
\hline Indonesia & $0.5(1)$ \\
\hline Kosovo & $0.5(1)$ \\
\hline Latvia & $0.5(1)$ \\
\hline Lebanon & $0.5(1)$ \\
\hline Luxemburg & $0.5(1)$ \\
\hline Macedonia & $0.5(1)$ \\
\hline Mexico & $0.5(1)$ \\
\hline Serbia & $0.5(1)$ \\
\hline Switzerland & $0.5(1)$ \\
\hline Turkey & $0.5(1)$ \\
\hline Not specified & $12.5(24)$ \\
\hline Total & 100 (192) \\
\hline
\end{tabular}

no difference in satisfaction between participants with and without German citizenship.

Foreign-national physicians were less satisfied with aspects related to human relations, such as "work atmosphere", "relationship with colleagues", "relationship with non-medical staff", and "social status". An exception was "equality of women and men", which foreignnational physicians were more satisfied with. Language difficulties may hinder immigrant physicians in Germany from "integrating into the team" and point to cultural barriers immigrant physicians may face when coming to Germany [14]. Immigrant physicians' professional socialization may differ from that of German physicians, leading to diverging ideas of who is responsible for which professional tasks and decisions [15]. If a foreignnational physician subsequently does not act as expected, German colleagues may interpret this as lack of competence or refusal to work [15]. This, together with language barriers and a high work load, may cause severe conflicts within the team [15]. A study from the USA showed that international medical graduates experienced workplace bias and discrimination [16]. It is conceivable that foreign-national physicians in Germany have similar experiences, subsequently impairing their work enjoyment and their satisfaction with the work atmosphere, relationship with co-workers, and social status. International medical graduates in the USA reported "limitations to professional opportunities" and were less satisfied with their careers than US medical graduates $[16,17]$. Again, similar phenomena, alongside difficulties with recognition of foreign degrees and qualifications by German authorities [13, 14], may contribute to foreignnational physicians' lower satisfaction with job security as well as social status.

Physicians' professional satisfaction is positively linked to their patients' satisfaction with care [6]. Similarly, a recent systematic review concludes that physicians' occupational well-being (including the aspect of job satisfaction) could contribute to quality of patient care in terms of better patient satisfaction, adherence to treatment recommendations, interpersonal aspects of care, and quality of overall care processes [18]. Foreign-national physicians are an important part of the German health care system: e.g. $20.8 \%$ of physicians practising in North Rhine-Westphalia in 2015 had a citizenship other than German (calculations based on [19] and [20]). Therefore, foreign-national physicians' occupational well-being, including job satisfaction, may influence quality of patient care in Germany.

\section{Limitations}

While citizenship is an indicator of migration, it does not permit differentiating between foreign-born and foreign-trained physicians, nor is it proof of being born in the country of citizenship. It is unknown how long foreign-national physicians had been living in Germany and whether they planned on staying permanently or for a limited time-period. As it was beyond the scope of this survey, the questionnaire did not address language skills. Therefore, it is not possible to evaluate the influence of language skills on job satisfaction in this sample of foreign-national physicians. In the context of the main aim of the study, which was to evaluate young physicians' wishes to leave patient care [9] and to go abroad for clinical work, physicians up to 40 years of age were invited to participate in this study. Larger, less age- 
Table 3 Work satisfaction of participants with and without German citizenship

\begin{tabular}{|c|c|c|c|}
\hline & German citizenship & Other citizenship & $p$ \\
\hline & M (SD; $95 \%$ Cl) & M (SD; $95 \% \mathrm{Cl})$ & \\
\hline Overall job situation & $3.41(0.94 ; 3.36-3.45)$ & $3.39(0.93 ; 3.25-3.53)$ & 0.799 \\
\hline Time for administrative tasks & $2.25(1.02 ; 2.21-2.30)$ & $2.30(1.04 ; 2.15-2.45)$ & 0.528 \\
\hline Time for family, friends, leisure activities & $2.47(1.12 ; 2.42-2.53)$ & $2.35(1.00 ; 2.21-2.50)$ & 0.155 \\
\hline Stress level at work & $2.71(1.02 ; 2.67-2.76)$ & $2.61(0.94 ; 2.47-2.74)$ & 0.164 \\
\hline Work load & $2.87(1.10 ; 2.82-2.92)$ & $2.78(1.03 ; 2.63-2.93)$ & 0.265 \\
\hline Possibility to treat patients as you deem optimal & $3.18(0.92 ; 3.14-3.23)$ & $3.40(0.93 ; 3.26-3.53)$ & 0.003 \\
\hline Training opportunities & $3.25(1.06 ; 3.20-3.30)$ & $3.26(1.08 ; 3.11-3.41)$ & 0.889 \\
\hline Career opportunities & $3.27(0.96 ; 3.23-3.32)$ & $3.36(0.95 ; 3.22-3.49)$ & 0.258 \\
\hline Intellectual stimulation at work & $3.54(0.94 ; 3.50-3.59)$ & $3.47(0.89 ; 3.34-3.60)$ & 0.290 \\
\hline Possibility to refer patients to specialists whenever you deem it necessary & $3.58(0.92 ; 3.54-3.63)$ & $3.72(0.84 ; 3.59-3.84)$ & 0.058 \\
\hline Work enjoyment & $3.68(0.91 ; 3.64-3.72)$ & $3.53(0.94 ; 3.39-3.66)$ & 0.028 \\
\hline Quality of the medical care you provide & $3.69(0.71 ; 3.66-3.72)$ & $3.78(0.75 ; 3.67-3.88)$ & 0.111 \\
\hline Income & $3.70(0.95 ; 3.66-3.75)$ & $3.62(0.92 ; 3.49-3.75)$ & 0.251 \\
\hline Equality of women and men & $3.71(1.03 ; 3.66-3.76)$ & $3.88(1.02 ; 3.73-4.02)$ & 0.038 \\
\hline Relationship with superiors & $3.75(1.00 ; 3.71-3.80)$ & $3.66(0.97 ; 3.52-3.80)$ & 0.215 \\
\hline Work atmosphere & $3.76(0.94 ; 3.72-3.81)$ & $3.54(0.99 ; 3.40-3.69)$ & 0.003 \\
\hline Social status & $3.77(0.91 ; 3.73-3.82)$ & $3.61(0.97 ; 3.47-3.75)$ & 0.020 \\
\hline Relationship/professional exchange with colleagues & $3.83(0.87 ; 3.78-3.87)$ & $3.67(0.90 ; 3.55-3.80)$ & 0.023 \\
\hline Relationship with patients & $3.94(0.65 ; 3.91-3.97)$ & $4.04(0.76 ; 3.93-4.14)$ & 0.046 \\
\hline Relationship with non-medical staff & $3.96(0.77 ; 3.92-3.99)$ & $3.73(0.86 ; 3.61-3.85)$ & $<0.001$ \\
\hline Job security & $4.04(0.94 ; 4.00-4.09)$ & $3.79(0.96 ; 3.66-3.93)$ & $<0.001$ \\
\hline
\end{tabular}

Means of 5-point Likert scales ( 1 = very dissatisfied to $5=$ very satisfied) were calculated. Participants with and without German citizenship were compared and $p$ values are shown. $M$ mean, $S D$ standard deviation, $C l$ confidence interval

restricted studies are needed to paint a comprehensive picture of foreign-national physicians' perspectives on their professional situation in Germany. Anonymization prevented characterization of those who refused participation.

\section{Conclusions}

In the present study, foreign-national physicians experienced less work enjoyment and were less satisfied with aspects mainly related to human relations, such as "work atmosphere", relationship with co-workers, and "social status". While in this analysis the reasons remain speculative, previous studies point to divergent professional socializations, language and cultural barriers, workplace bias and discrimination as potential explanations [14-16]. There is an urgent need for further research exploring determinants of job satisfaction of foreign-national physicians practicing in Germany as their professional well-being may influence quality of patient care. Potential measures to improve foreign-nationals' job satisfaction may include extended periods of adjustment when starting work in the German health care system, language classes and courses aiding migrant physicians with understanding and adjusting to the German culture. Importantly, German physicians working with foreign-national colleagues may also benefit from educational measures teaching cross-cultural competence and awareness, in an effort to facilitate effective work in a multi-national team.

\section{Additional file}

Additional file 1: Study questionnaire. (PDF $198 \mathrm{~kb}$ )

\section{Acknowledgements}

We thank the State Chamber of Physicians of Saxony, especially the former president Prof. Dr. Schulze, for their support in conducting the study. We are also grateful to the AOK Bundesverband for financing the study.

\section{Funding}

The study was funded by the AOK Bundesverband (project number: BGADL-0051).

\section{Availability of data and materials}

The data are available upon request. The questionnaire was added as Additional file 1.

\section{Authors' contributions}

BP participated in study design, acquisition and analysis of data, and drafted the manuscript. KK contributed to data analysis and drafting of the manuscript. ML participated in study design and data analysis, and revised 
the manuscript critically for important intellectual content. HHK participated in data analysis and revised the manuscript critically for important intellectual content. SRH conceived of the study, participated in study design and revised the manuscript critically for important intellectual content. All authors contributed to data interpretation. All authors read and approved the final manuscript.

\section{Competing interests}

The authors declare that they have no competing interests.

\section{Consent for publication}

Not applicable.

\section{Ethics approval and consent to participate}

Please see section Methods "Study population and study design":

The paper-pencil questionnaire was accompanied by a letter informing that returning the completed questionnaire would be regarded as giving informed consent to participation. The ethics committee of the University of Leipzig (Ethik-Kommission an der Medizinischen Fakultät der Universität Leipzig) approved the study (reference number: 262-12-13082012).

\section{Author details}

${ }^{1}$ Institute of Social Medicine, Occupational Health and Public Health, University of Leipzig, Philipp-Rosenthal-Str. 55, 04103 Leipzig, Germany. ${ }^{2}$ State Office of Tax and Finance (Landesamt für Steuern und Finanzen), Occupational Health Management, Stauffenbergallee 2, 01099 Dresden, Germany. ${ }^{3}$ Department of Health Economics and Health Services Research, University Medical Center Hamburg-Eppendorf, Martinistr. 52, 20246 Hamburg, Germany.

Received: 17 June 2016 Accepted: 16 August 2016

Published online: 30 August 2016

\section{References}

1. Aluttis C, Bishaw T, Frank MW. The workforce for health in a globalized context-global shortages and international migration. Glob Health Action. 2014:7:23611. doi:10.3402/gha.v7.23611.

2. Bundesärztekammer. Ärztestatistik 2014: http://www.bundesaerztekammer de/fileadmin/user_upload/downloads/pdf-Ordner/Statistik2014/ Stat14AbbTab.pdf. Accessed 16 Jun 2016

3. Ognyanova D, Busse R. A destination and a source: Germany manage regional health workforce disparities with foreign medical doctors. In: Wismar M, Maier CB, Glinos IA, Dussault G, Figueras J, editors. Health Professional Mobility and Health Systems. Evidence from 17 European countries. European Observatory on Health Systems and Policies. 2011: 211-41.

4. Sächsische Landesärztekammer. Arztzahlen in Sachsen 2012: https://www. slaek.de/de/04/pressemitteilungen/2013/024-Arztzahlen.php. Accessed 16 Jun 2016

5. Hänel P, Jansen E. (K)ein Ort zum Niederlassen. Dtsch Ärztebl. 2014;111: A-2004/B-1706/C-1632

6. Haas JS, Cook EF, Puopolo AL, Burstin HR, Cleary PD, Brennan TA. Is the professional satisfaction of general internists associated with patient satisfaction? J Gen Intern Med. 2000;15:122-8.

7. Pantenburg B, König HH, Riedel-Heller SG. [Job satisfaction among young physicians working in psychiatric and psychosomatic care - results of a survey in Saxony, Germany]. Psychiatr Prax. 2015. [Epub ahead of print].

8. Pantenburg B, Luppa M, König HH, Riedel-Heller SG. Burnout among young physicians and its association with physicians' wishes to leave: results of a survey in Saxony, Germany. J Occup Med Toxicol. 2016;11:2. doi:10.1186/ s12995-016-0091-z.

9. Pantenburg B, Luppa M, König HH, Riedel-Heller SG. Young physicians thoughts about leaving patient care-results of a survey in Saxony, Germany. Gesundheitswesen. 2014;76:406-12. doi:10.1055/s-0034-1381986.

10. Bovier PA, Perneger TV. Predictors of work satisfaction among physicians. Eur J Public Health. 2003:13:299-305.

11. Janus K, Amelung VE, Gaitanides M, Schwartz FW. German physicians "on strike"-shedding light on the roots of physician dissatisfaction. Health Policy. 2007:82:357-65. doi:10.1016/j.healthpol.2006.11.003.

12. Köhler S, Kaiser R. Junge Ärzte - Ausstieg aus der Patientenversorgung? Hessisches Ärzteblatt. 2003;9:462-4.
13. Fellmer S, for the EU Monitoring and Advocacy Program (EUMAP), Open Society Institute. Germany Restricted the Freedom of Movement for Polish Citizens - but Does It Matter? http://pdc.ceu.hu/archive/00003936/01/ fellmer.pdf. Accessed 16 Jun 2016

14. Ognyanova D, Young R, Maier CB, Busse R. Why do health professionals leave Germany and what attracts foreigners? A qualitative study. In: Buchan J, Wismar M, Glinos IA, Bremner J, editors. Health Professional Mobility in a Changing Europe. New dynamics, mobile individuals and diverse responses. European Observatory on Health Systems and Policies. 2014:203-32.

15. Jansen $E$, Schnepf T, Hänel P. [Diverging professional socialization of migrated physicians]. Public Health Forum. 2015:23:116-8.

16. Chen PGC, Nunez-Smith M, Bernheim SM, Berg D, Gozu A, Curry LA. Professional experiences of international medical graduates practicing primary care in the United States. J Gen Intern Med. 2010;25:947-53. doi:10.1007/s11606-010-1401-2.

17. Chen PG, Curry LA, Nunez-Smith M, Bradley EH, Desai MM. Career satisfaction in primary care: a comparison of international and US medical graduates. J Gen Intern Med. 2012;27:147-52. doi:10.1007/s11606-011-1832-4.

18. Scheepers RA, Boerebach BC, Arah OA, Heineman MJ, Lombarts KM. A Systematic Review of the Impact of Physicians' Occupational Well-Being on the Quality of Patient Care. Int J Behav Med. 2015;22:683-98. doi:10.1007/s12529-015-9473-3.

19. Bundesärztekammer. Ärztestatistik 2015: http://www.bundesaerztekammer de/fileadmin/user_upload/downloads/pdf-Ordner/Statistik2015/ Stat15AbbTab.pdf. Accessed 16 Jun 2016

20. Gesundheitsberichterstattung des Bundes. Ärztinnen und Ärzte, Ausländer, BÄK - Bei den Ärztekammern registrierte ausländische Ärztinnen und Ärzte (Anzahl). 2015. http://www.gbe-bund.de/gbe10/trecherche.prc_them_ rech?tk=14501\&tk2=15401\&p_uid=gast\&p_aid=13500380\&p_ sprache=D\&cnt_ut=1\&ut=15401. Accessed 06.07.2016

\section{Submit your next manuscript to BioMed Central and we will help you at every step:}

- We accept pre-submission inquiries

- Our selector tool helps you to find the most relevant journal

- We provide round the clock customer support

- Convenient online submission

- Thorough peer review

- Inclusion in PubMed and all major indexing services

- Maximum visibility for your research

Submit your manuscript at www.biomedcentral.com/submit 